\title{
Brain and Cognition
}

\author{
Editor: Harry A. Whitaker \\ Associate Editor: Alfonso Caramazza \\ Full Rate - UK: $£ 31.80$ Overseas: $\$ 54.00$ \\ Personal Rate* - UK: $£ 17.70$ Overseas: $\$ 30.00$
}

Publication: Quarterly Subscription: Volume 1, 1982

(*Orders must be placed directly with the publisher and paid for out of personal funds.)

This new journal was created in response to the significant growth in research and interest in the nonlinguistic aspects of neuropsychology during the last decade. As a complement to Brain and Language, which focuses on language mechanisms, Brain and Cognition will disseminate the latest research findings and provide critical discussion on other aspects of brain structure and function including: motor sensory processes, visual and spatial processes, memory, emotion, sex differences, hemispheric differences, praxis, attention, consciousness, and cognitive processes.

The journal will present research papers, clinical case histories, reviews, notes and commentaries, and book reviews that make scholarly contributions in their own right. Brain and Cognition will occasionally devote an entire issue to a se! of theoretical and empirical papers on a single topic.

\section{Brain and Language}

\author{
Editor: Harry Whitaker \\ Associate Editor: Alan Rubens
}

Publication: Six issues per year Subscription: Volumes 15-17, 1982

Full Rate - UK: $£ 75.90$ Overseas: $\$ 129.00$

Personal Rate* - UK: $\$ 40.60$ Overseas: $\$ 69.00$

(*Orders must be placed directly with the publisher and paid for out personal funds.)

Brain and Language publishes original, theoretical, clinical, and experimental papers on human language and communication - speech, hearing, reading, writing, higher language functions, nonverbal communication - as they relate to any aspect of brain and brain function. The articles include research reports, case histories, critical reviews of pertinent research areas, book reviews, and short scholarly notes. As a genuine interdisciplinary journal, Brain and Language will be invaluable to researchers and practitioners in neurology, linguistics, neurophysiology, neuropsychology, neuroanatomy, psychiatry, neurosurgery, speech pathology, audiology, and related specialities.

\section{Coupon}

\section{Brain and Cognition}

Brain and Language

Please tick
To: Jane Lawrence Academic Press Inc. (London) Ltd 24.28 Oual Road London NW1 7DX, England $\mathrm{ZW/10.82/A131}$

Please send me a sample copy and subscription details of Brain and Cognition Please send me a sample copy and subscription details of Brain and Language

Signature .............. Name (Capitals) . . . . . . . . . .

Address 


\section{Assessing the Handicaps and Needs of Mentally Retarded Children \\ edited by Brian Cooper \\ November 1981, xiv + 270pp., f11.80 (UK only) /\$24.50, 0.12.188020.6}

The term 'mental retardation' is used to describe a wide range of neurological impairments, developmental disorders, learning difficulties and behaviour disturbances. This book attempts to dissuade this often detrimental blanket labelling by examining recent scientific progress in a number of areas relevant to mental retardation in children, and will be particularly welcome in the International Year of the Disabled.

The Library of Analytical Psychology Volume 5

\section{Analysis, Repair and Individuation \\ Kenneth Lambert \\ September 1981, xvi + 234pp., f12.50 (UK on/y) / \$30.00, 0.12.434640.5}

Recent convergences between psychoanalysis and analytical psychology in clinical practice have enabled Jungians concerned with individuation to increase their use of the analysis of resistance and counter-resistance, reconstruction, transference and counter-transference, the formation of object-relationships and internal objects, and dreams. This theme is elaborated on in some detail in this new volume in the Library of Analytical Psychology, which also discusses the attitude required of the analyst and includes a glossary of terms used in presentday analytical psychology in London.

\section{Drug Problems in Britain: A Review of Ten Years \\ edited by Griffith Edwards and Carol Busch \\ Ju/V/August 1981, $x+334 p p ., £ 14.80$ (UK only) / \$36.00, 0.12.232780.2}

The contributors to this book address three central issues: the need for an historical perspective on drug addiction, what the mass of research indicates when sifted and analysed, and the nature of government policies. Papers include an extensive review of the historical background of the legal and administrative structure; a definitive description of the Home Office Index as a basic monitoring system; contributions on the epidemiology of general and clinical populations; and a critical review of longitudinal studies in drug dependence and the 'career' perspective. Papers on morbidity and mortality, criminal involvement, aetiological theories, and health education policies are also included.

\section{Marijuana Use and Social Control}

\section{John Auld}

May 1981, xviii + 238pp., f11.80 (UK only) / \$28.50, 0.12.068280.X

Seeking an explanation for changes in patterns of marijuana use that emerged in the early 1970's, Marijuana $U_{s e}$ and Social Control discusses the impact and effectiveness of lawenforcement strategies, examines the social settings in which marijuana was used, and points to the effects of the expectations of users on their experience with the drug. It is this last issue, together with the social and cultural meanings of marijuana, which forms the core of this book. Finally $\mathrm{Dr}$ Auld illustrates the need for a reexamination of the relationship between marijuana use and social control.

APL 1294

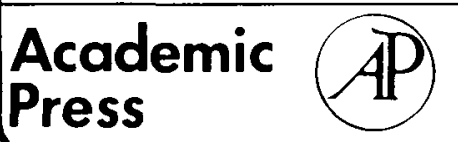

A Subsidiary of Harcourt Brace Jovanovich, Publishers London New York Toronto Sydney San Francisco 24-28 Oval Road, London NW1 7DX, England 111 Fifth Avenue, New York, NY 10003, USA 


\section{Instructions to Authors}

1. Submission. Articles, written in English and not submitted for publication elsewhere, may be sent to any one of the following editors: Dr Ray Hadgson, Addiction Research Unit, Institute of Psychiatry, Denmark Hill, London SE5 8AF, U.K.; Dr William Yule, Psychology Department, Institute of Psycbiatry, De Crespigny Park, London SE5 8AF, U.K., Dr G. Terence Wilson, Graduate School of Applied and Professional Psychology, Rutgers University, Busch Campus, P.O. Box 819, Piscataway, New Jersey 08854, U.S.A.

Manuscripts will be sent out for review exactly as submitted. Authors who want a blind review should mark two copies of their article "review copy" omitting from these copies details of authorship.

2. Manuscript preparation. Articles must be typed double-spaced throughout on standard sized paper (preferably A4) allowing good margins all round. Three copies must be submitted, and the author should retain a further copy. Original figures must be supplied at the time of submission.

Abbreviations where used must be standard. The Système Internationale (SI) should be used for all units; where metric units are used the SI equivalent must also be given. Probability values and power statistics should be given with statistic values and degrees of freedom [e.g. $F(1,34)=123.07, P<0.001]$, but such information should preferably be included in tables rather than the main text.

Spelling must be consistent within an article, either using British usage (The Shorter Oxford English Dictionary), or American usage (Webster's New Collegiate Dictionary). However, spelling in the list of references must be literal to each original publication.

Details of style not specified here may be determined by reference to the Publication Manual of the American Psychological Association or the Style Manual for Biological Journals.

Articles should conform to the following scheme:

(a) Title page. The title should phrase concisely the major issues. Author(s) to be given with departmental affiliations and addresses, grouped appropriately. A running head of no more than 40 characters should be indicated.

(b) Summary. This should summarize the article in no more than 200 words.

(c) Text. This should begin with an introduction, succinctly introducing the point of the paper to those interested in the general area of the journal. References within the text should be given in the form Jones and Smith (1973). Three or more authors should be given as Williams et al. (1973). Authors of the same surname should be distinguished by their initials. The approximate positions of tables and figures should be indicated in the text. Footnotes should be avoided where possible.

(d) Reference note( $(s)$. A list of all cited unpublished or limited circulation material, numbered in order of appearance in the text, giving as much information as possible about extant manuscripts.

(e) References. All citations in the text should be listed in strict alphabetical order according to surnames. Multiple references to the same author should be listed chronologically, using a, b, etc., for entries within the same year. Formats for journal articles, books and chapters should follow these examples:

BeCKer, M. R. and Green, L. W. (1975). A family approach to compliance with medical treatment: A selective review of the literature. International Journal of Health Education 18, 173-182.

THORP, R. G. and WETZEL, R. J. (1969). Bebaviour Modification in the Natural Environment, New York: Academic Press.

Roskies, E. and Lazarus, R. S. (1980). Coping theory and the teaching of coping skills. In Bebavioural Medicine: Changing Healtb Lifestyles, P. O. Davidson and S. M. Davidson (Eds), New York: Brunner/Mazel.

(f) Footnotes. The first, and preferably only, footnote will appear at the foot of the first page of each article, and subsequently may acknowledge previous unpublished presentation (e.g. dissertation, meeting paper), financial support, scholarly or technical assistance, or a change in affiliation. Its concluding (or only) paragraph must be the name and full mailing address of the author to whom reprint requests or other inquires should be sent.

(g) Tables. Tables should be numbered and given explanatory ritles.

(h) Figure captions. Numbered captions should be typed on a separate page.

(i) Figures. Original drawings or prints must be submitted for each line or half-tone illustration. Figures should be clearly labelled.

3. Proofs, Reprints and Copyright. Proofs of accepted articles will be sent to authors for the correction of printers' errors; author's alterations may be charged. Authors submitting a manuscript do so on the understanding that if it is accepted for publication exclusive copyright in the paper shall be assigned to the Society. In consideration of the assignment of copyright, 25 copies of each paper will be supplied. Further reprints may be ordered at extra cost; the copyright assignment form and the reprint order form will be sent with the proofs. The publishers will not put any limitation on the personal freedom of the author to use material contained in the paper in other works. 
